\title{
Chronic pancreatitis with pancreatic duct stricture and calculi treated by fully covered self-expandable metal stent placement and intraductal pancreatoscopy- guided laser lithotripsy
}

A 38-year-old man with chronic pancreatitis caused by heavy alcohol consumption presented with recurrent abdominal pain due to underlying pancreatic duct calculi and stricture of the main pancreatic duct ( $>$ Fig. 1 a). Endoscopic cholangiopancreatography (ERCP) was performed and a plastic pancreatic stent was inserted, which relieved the pain. Attempts at stricture dilation with a dilation balloon ( $\mathbf{F i g . 1} \mathbf{b}$ ) and insertion of multiple plastic stents, and fragmentation of the pancreatic duct stones by extracorporeal shockwave lithotripsy (ESWL) were unsuccessful.

A $6 \times 90-\mathrm{mm}$ fully covered self-expandable metal stent (FCSEMS) designed for pancreatic duct drainage (Niti-S Bumpy Pancreatic Stent; Taewoong Medical, Gyeonggi-do, South Korea) was therefore inserted to dilate the stricture ( Fig.1 c). When the FCSEMS was removed 3 months later the stricture had resolved and ERCP with intraductal pancreatoscopy (Spyglass; Boston Scientific Corp., Marlboro, Massachusetts, USA) and Holmium-yttrium aluminum garnet laser lithotripsy could be successfully performed (>Fig.1d; $>$ Video $\mathbf{1}$ ). There were no procedure-related complications.

Insertion of multiple plastic pancreatic stents is the standard approach to dilate and achieve long-term resolution of dominant pancreatic duct strictures [1]. ESWL is generally required for pancreatic stone fragmentation prior to ERCP and stone extraction [2]. In a pilot study of 32 patients that described the use of the Niti-S Bumpy pancreatic stent, which is specifically designed with antimigration features to treat benign pancreatic strictures, successful stricture resolution was achieved in all patients after temporary placement for 3 months, with no stent migration or adverse effects [3].
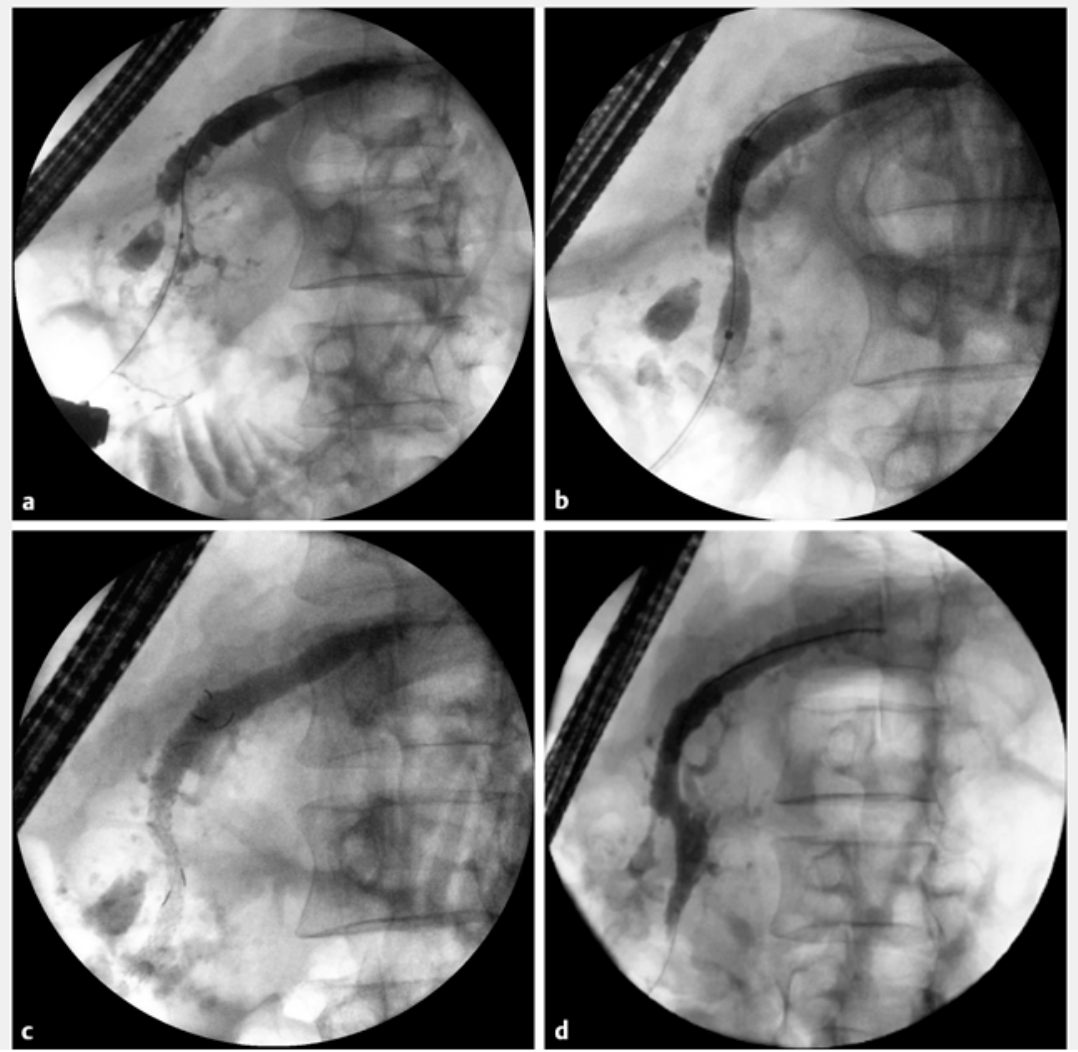

- Fig. 1 Pancreatogram images showing: a a pancreatic duct stricture at the neck of the pancreas and a pancreatic duct stone located proximally to the stricture; $\mathbf{b}$ persistence of the pancreatic stricture despite balloon dilation; $\mathbf{c}$ a fully covered self-expandable metal stent inserted across the pancreatic stricture; $\mathbf{d}$ resolution of the pancreatic stricture with the pancreatic stone having been successfully extracted.

The limited data on the use of laser lithotripsy for pancreatic duct calculi have suggested it may be safe and effective. A US multicenter study with 28 patients reported successful resolution in $79 \%$ of patients, with one episode of post-ERCP pancreatitis [4].

In our patient, both FCSEMS placement and pancreatoscopy with laser lithotripsy were required to achieve successful endoscopic therapy.

Endoscopy_UCTN_Code_TTT_1AR_2AH

\section{Competing interests}

None

The Author

\section{Tiing Leong Ang}

Department of Gastroenterology and Hepatology, Changi General Hospital, Singapore 


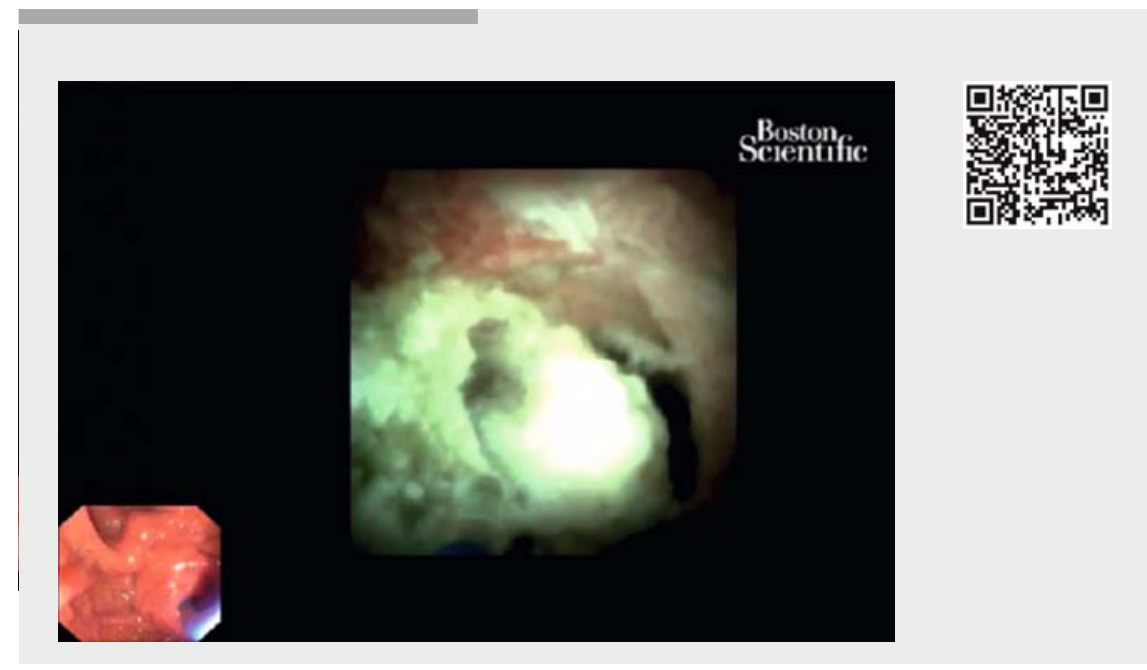

$\checkmark$ Video 1: Endoscopic cholangiopancreatography is performed with balloon dilation of a pancreatic stricture followed by insertion of a fully covered self-expandable metal stent. After subsequent removal of the stent, intraductal pancreatoscopy with laser lithotripsy is performed and the stone is successfully extracted.

[2] Maydeo A, Soehendra N, Reddy N et al. Endotherapy for chronic pancreatitis with intra-canalar stones. Endoscopy 2007; 39: $653-658$

[3] Moon SH, Kim MH, Park DH et al. Modified fully covered self-expandable metal stents with anti-migration features for benign pancreatic-duct strictures in advanced chronic pancreatitis, with a focus on the safety profile and reducing migration. Gastrointest Endosc 2010; 72: 86-91

[4] Attwell AR, Patel S, Kahaleh M et al. ERCP with per-oral pancreatoscopy-guided laser lithotripsy for calcific chronic pancreatitis: a multicenter U.S. experience. Gastrointest Endosc 2015; 82: 311-318

\section{Bibliography}

DOI https://doi.org/10.1055/s-0043-105570

Endoscopy 2017; 49: E145-E146

(c) Georg Thieme Verlag KG

Stuttgart · New York

ISSN 0013-726X

\section{Corresponding author}

\section{Tiing Leong Ang, MD}

Department of Gastroenterology and Hepatology, Changi General Hospital, 2 Simei Street 3, Singapore 529889, Republic of Singapore

tiing_leong_ang@cgh.com.sg

\section{References}

[1] Costamagna G, Bulajic M, Tringali A et al. Multiple stenting of refractory pancreatic duct strictures in severe chronic pancreatitis: long-term results. Endoscopy 2006; 38: $254-259$

\section{ENDOSCOPY E-VIDEOS}

https://eref.thieme.de/e-videos

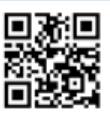

Endoscopy E-Videos is a free access online section, reporting on interesting cases and new

techniques in gastroenterological endoscopy. All papers include a high quality video and all contributions are freely accessible online.

This section has its own submission website at https://mc.manuscriptcentral.com/e-videos 